Melina M. Nikolić*

https://doi.org/10.18485/analiff.2017.29.1.7

\title{
POKUŠAJ DEFINISANJA KONFRONTACIONOG INTERVJUA
}

Diskurs moći je već decenijama predmet interesovanja velikog broja naučnih disciplina, a posebno kritičke analize diskursa. Predstavnici ove lingvističke discipline smatraju da je institucionalni diskurs izvor govora moći, a naročitu pažnju posvetili su medijskom diskursu. Analiziran je veliki broj medijskih formi, a posebna pažnja posvećena je intervjuu. Međutim, intervju je uglavnom analiziran kao forma koja se po sebi podrazumeva i istraživači se gotovo uopšte nisu bavili definisanjem različitih vidova medijskih intervjua. Predmet ovog rada je pokušaj definisanja specifične forme televizijskog intervjua koji je sve prisutniji na televizijskim programima širom sveta putem kojeg intervjueri, kao predstavnici medija, pokušavaju da od intervjuisane osobe, koja se nalazi u centru pažnje javnosti, dobiju ne samo one informacije koje je intervjuisani spreman da obelodani, već i one koje pubika očekuje da čuje, a koje intervjuisana osoba iz raznih razloga nije spremna da otkrije. Da bismo jasno pokazali o kakvom je diskursu reč razjasnićemo pojmove intervjua, instituicionalnog diskursa, konfrontacije i pozicioniranja sagovornika u takvom tipu diskursa iz perspektive kritičke analize diskursa i analize konverzacije, i na osnovu analize pojedinačnih elemenata i poređenja sa klasičnim intervjuom, pokušaćemo da damo sveobuhvatnu definiciju konfrontacionog medijskog intervjua.

Ključne reči: intervju, institucionalni diskurs, konfrontacija, konfrontacioni diskurs, kritička analiza diskursa, analiza konverzacije

Savremeni način života, brz tempo u svim oblastima ljudskog delovanja kao i obilje podataka kojima smo izloženi sve više nas upućuje na medije kao glavne izvore informacija. Pošto smo sve više usmereni na medije, naročito na televiziju, koja je sveprisutna u najširim slojevima društva, povećava se mogućnost uticanja na javno mnenje putem tog medija. Političari, ekonomisti, naučnici, sportisti, aktivisti, ekolozi, i predstavnici raznih drugih profesija, sve su prisutniji u našim domovima, a

nikolicmelina@ikomline.net;melina.nikolic@alfa.edu.rs 
njihove reči se slušaju i ponavljaju, potvrđuju ili osporavaju. Televizija im omogućava da utiču na mišljenje javnosti i na taj način pridobiju podršku za sebe ili kritikuju protivnike, konkurenciju ili opoziciju, ali se samim tim izlažu većem riziku od razotkrivanja ili diskreditacije. Zato moraju da obrate posebnu pažnju na diskurs koji koriste u javnim nastupima. Tako se diskursi oblikuju i dobijaju specifične karakteristike. Najbolji primer je politički diskurs, koji je postao prepoznatljiv po ,proračunatom dizajnu“ (Fairclough i Wodak, 1997: 259). Stoga je potrebno te diskurse detaljno kritički analizirati i razotkriti. Jedan od čestih oblika diskursa na televiziji i najzgodniji način da se moć diskursa sprovede u delo je konfrontacioni intervju. Da bismo imali jasnu sliku o kakvom je diskursu reč razjasnićemo pojmove intervjua, instituicionalnog diskursa, konfrontacije i pozicioniranja sagovornika u takvom tipu diskursa. Cilj nam je da pokušamo da damo sveobuhvatnu definiciju konfrontacionog intervjua kao specifične forme intervjua sve prisutnijeg na televizijskim programima širom sveta putem kojeg intervjueri, kao predstavnici medija, pokušavaju da od intervjuisane osobe, koja se nalazi u centru pažnje javnosti, dobiju ne samo one informacije koje je intervjuisani spreman da obelodani, već i one koje publika očekuje da čuje, a koje intervjuisana osoba iz raznih razloga nije spremna da otkrije.

\section{Pojam intervjua i definicije}

Intervju je specifičan oblik ljudske interakcije koji nalazimo u medijima, u preduzećima i ustanovama, sudnici, lekarskoj ordinaciji, učionici, policijskoj stanici, itd. Ukratko, intervju se javlja u institucionalnom diskursu u situacijama gde jedna strana postavlja pitanja, a druga na njih mora da odgovara. Mada se u različitim kontekstima različito naziva (intervju, televizijski intervju, saslušanje, razgovor za posao, i slično), svi navedeni oblici interakcije mogu se odrediti zajedničkim terminom intervju, i imaju osnovne zajedničke karakteristike: bar dva učesnika u razgovoru, od kojih jedan postavlja pitanja, a drugi na njih odgovara; zatim, statusno različite uloge, asimetrične; i konačno, cilj razgovora, koji može biti zajednički ili pak potpuno suprotan.

Intervju koji leži u osnovi konfrontacionog intervjua kojim se bavimo u ovom radu je medijski intervju, tj. intervju koji se vodi radi objavl-

jivanja u nekom mediju (štampa, radio, televizija, internet), a namenjen je širokoj publici. Intervju je već decenijama osnovno novinarsko sredstvo kako za prikupljanje informacija, tako i za informisanje javnosti. Zbog 
razvoja medija intervju je postao uobičajena forma u koju se ,vesti pakuju za javnost" (Heritage and Clayman, 2010: 215).

Ovde moramo terminološki odrediti pojam intervjua koji je predmet našeg proučavanja. Naime u literaturi na engleskom jeziku taj tip intervjua naziva se news interview, što podrazumeva njegovu osnovnu karakteristiku, a to je da javnost informiše, da obezbedi vesti, novosti. U literaturi na srpskom jeziku, kao što će se videti iz definicija i navoda iz naše literature, ne postoji usklađenost terminologije, pa se taj tip intervjua naziva medijski intervju (što je preširoko određenje), televizijski intervju (što je preusko, jer intervju podrazumeva i radijski i on-line intervju), ili najčešće samo intervju (što je donekle opravdano, jer je značenje reči intervju u srpskom jeziku znatno uže nego u engleskom i ne podrazumeva sve vrste intervjua kao u engleskom). Opredelili smo se za termin klasični intervju, ili intervju pitanje - odgovor, prema definiciji koju daje Veselin Kljajić (2009), mada ćemo zbog ekonomičnosti koristiti samo termin intervju, pošto je u svetlu ovog rada potpuno odgovarajući.

Intervju, i kao metod za prikupljanje informacija i kao novinarski žanr, počeo je da se razvija ka današnjem obliku intervjua od sredine 50ih godina XX veka. Do tada se živa reč u medijima uglavnom svodila na čitanje napisanog teksta. Intervjueri su bili jedva nesto više od ,respectful prompters“ (Wedell, 1968) koji su postavljali intervjuisanim gostima „meka“ pitanja u intervjuima koji su u najvećem broju slučajeva bili očigledno unapred pripremljeni i lišeni bilo kakve spontanosti (Day, 1961). Tek sa pojavom Nezavisne televizije u Britaniji koja je stavila tačku na monopol BBC-ja ${ }^{2}$ u izveštavanju, intervju počinje da se menja. Novi tip intervjua je istraživački, agresivniji i nije unapred pripremljen, odnosno, intervjuisani nije unapred obavešten koja će mu pitanja biti postavljena. Odgovori se ne prihvataju takvi kakvi su bez rezerve, već se preispituju, razjašnjavaju i preformulišu ako je potrebno. Stil ispitivanja postaje direktniji, istraživački i dubinski. Shodno tome, intervju postaje fleksibilniji, životniji, i veoma uticajan instrument novinarskog ispitivanja. (Heritage, 1985: 113). ${ }^{3}$

2 Mediji su morali da se pridržavaju zakonske obaveze o nepristrasnosti u izveštavanju o tekućim događajima, i to su usko shvatali tako da se su se prvenstveno držali izveštavanja o činjenicama, i isključivali iznošenje ličnog mišljenja. Tako je ovo tumačenje zakona sprečavalo razvijanje istraživačkog novinarstva. (Heritage, 1985)

3 O razlozima za promene u načinu vođenja intervjua videti dalje u poglavlju o intrevjuu kao institucionalnom diskursu. 
U svojoj knjizi u kojoj se bavi intervjuom Kljajić navodi: „Ni u Srbiji, niti bilo gde u svetu ne postoji ni jedna objavljena studija, disertacija ili udžbenik, odnosno knjiga koja na jedan zaokružen način posmatra intervju bilo kao metod, kao 'građu', kao faktografski, odnosno interpretativni oblik novinarskog izražavanja.“ (Kljajić, 2009: 9). Ipak, mnogi su autori obrađivali intervju i dali različite definicije od kojih ćemo navesti samo neke relevantne za ovaj rad.

U Vujaklijinom leksikonu data je definicija intervjua koja se prvenstveno odnosi na medijski intervju. Intervju je definisan kao ,razgovor, ispitivanje; naročito: razgovor između saradnika nekog lista i kakve istaknute ličnosti iz javnog života o aktuelnim pitanjima, koji će taj saradnik docnije objaviti u svom listu.“ (1966: 362). Definisanjem glagola intervjuisati, međutim, ograničava se shvatanje pojma konteksta koji je ključan za precizno određivanje intervjua: ,posetiti nekoga u cilju ispitivanja njegovog mišljenja“ (1966: 362), ali se ovde navodi cilj intervjua. Osoba koji vodi intervju naziva se intervjuist i definisana je na sledeći način: „saradnik, reporter nekog lista koji, u razgovoru sa kakvim istaknutim državnikom, umetnikom, naučnikom itd., gleda da postavljanjem pitanja dozna njegovo mišljenje o važnim dnevnim pitanjima da bi ga objavio u listu.“"(1966: 362).

Dušan Đurić u Novinarskoj enciklopediji na sledeći način definiše intervju: ,razgovor koji se vodi radi objavljivanja u medijima. Latinski inter znači i među, između; engleska reč view znači pogled, viđenje, razmatranje, ispitivanje, gledište. Sva ta značenja govore o suštini intervjua kao žanra.“(1997: 270) Đurić daje još neke definicije intervjua, mada ne navodi izvore. „1. Novinarski žanr u kome se sadržaj izražava u obliku pitanja i odgovora. 2. Izveštaj o razgovoru koji ima karakter saznavanja novosti, novih činjenica i objašnjenja. 3. Sled pitanja i odgovora koji se objavljuju za najširu javnost. 4. Saznavanje i objavljivanje činjenica i tumačenja koje novinar dobija od ličnosti dobro obaveštene o temi o kojoj novinar želi da obavesti javnost.“ (1997: 270). Kao što možemo da vidimo, iz ovih definicija se mogu izvesti samo neke karakteristike intervjua. Forma intervjua se određuje kao pitanje - odgovor; jasno je da je to razgovor, dakle ima bar dva učesnika; cilj intervjua je saznavanje novosti i činjenica i njihovo objavljivanje u medijima. Ne vidimo koliko je učesnika potrebno za intervju niti kakav je njihov status.

U Leksikonu filmskih i televizijskih pojmova nalazimo sledeću definiciju: „Intervju (engl. Interview) - Razgovor u vidu pitanja i odgovora 
između reportera-novinara i sagovornika. [...] Ima za cilj da se rasvetli neki problem radi informacije i tumačenja određenog problema onako kako ga shvata intervjuisani. Dobar intervju poseduje: izbor teme koja je najčešće aktuelna, izbor ličnosti koja svojom stručnošću i erudicijom može dati valjane odgovore, i pitanja koja su tako sročena da pobuđuju pažnju i intervjuisane osobe i auditorijuma." (1993: 248) Televizijski intervju je definisan kao ,razgovor o nekoj zanimljivoj ili aktuelnoj temi između TV novinara i jednog ili više sagovornika koji, manje ili više autoritativno, odgovaraju na postavljena pitanja.“ (1993: 248). Ova definicija je preciznija od prethodnih što se tiče učesnika u razgovoru - reporter-novinar i jedan ili više sagovornika koji moraju biti relevantni za temu; teme su zanimljive ili aktuelne, a ciljevi intervjua su da se javnost informiše o nekom problemu i da se taj problem razjasni.

Kljajić daje svoju definiciju iz ugla novinarstva: „klasični ili intervju pitanje-odgovor jeste faktografski oblik novinarskog izražavanja, gde se u formi dijaloga kroz pitanja i odgovore, a u razgovoru sa određenom ličnošću, javnosti pružaju informacije o pojavi, događaju, problemu ili čak samoj ličnosti od društvenog interesa“. Pored toga on kaže da se, kad je reč o izboru ličnosti koje se intervjuišu, „načešće radi o ličnostima u žiži intersovanja javnosti, ili onima koji 'imaju šta da kažu'.“ (2009: 66). Kljajić daje i podelu intervjua kao metoda i kao žanra. Nas interesuje intervju kao žanr, a on se deli na (1) klasični/tematski intervju, ili intervju pitanje-odgovor, i (2) intervju-portret, tj. intervju-profil. Klasični intervju se još naziva i tematski, jer se u njemu kroz formu pitanja i odgovora prezentuje razgovor o određenoj temi. Iz ovog oblika intervjua razvio se i konfrontacioni intervju.

Definicije intervjua, doduše nepotpune, možemo naći kod autora koji su se intervjuom bavili iz lingvističke perspektive. Jednu od najopštijih i najcitiranijih daje Schegloff: „one party asks questions and the other party gives answers“. (1992:118). Clayman i Heritage smatraju da je intervju pre svega:

a course of interaction to which the participants contribute on a turnby-turn basis, for the most part by asking and answering questions. [...] particular themes are expressed within each successive contribution, but these contributions are not merely understood in terms of their thematic content. They are also understood in terms of how they bear on the unfolding interactional "game" being played by interviewer and interviewee. (2002: 13)

Medijski intervju se po Heritage-u i Clayman-u razlikuje od ostalih medijskih žanrova koji se zasnivaju na razgovoru po ,unique constellation 
of participants, subject matter, and interactional form.“ (2010: 215) Intervjueri su obično priznati profesionalni novinari, a intervjuisane ličnosti su javni funkcioneri, stručnjaci ili drugi koji su na neki način vezani za tekuće događaje. Razgovor se fokusira na takve događaje, relativno je formalnog karaktera, i vodi se prvenstveno u formi pitanja i odgovora. (2010: 215). Ovo je i najpotpunija definicija medijskog intervjua koja sagledava u svim bitnim tačkama intervju kao komunikativni događaj.

Struktura intervjua se svodi na smenjivanje pitanja i odgovora. Pitanja ne moraju imati interogativnu formu, već mogu biti, na primer, i deklarativne rečenice. Bez obzira na formu intervjuerove replike ona uvek ima funkciju pitanja na koje intervjuisana osoba mora da odgovori. Isto tako i svaka replika intervjuisanog ima funkciju odgovora, bilo u kom obliku da je data.

\section{Učesnici u intervjuu}

Mada većina definicija intervjua govori o učesnicima u konverzaciji, nigde se njihove uloge ne definišu dovoljno precizno. Nessa Wolfson u definiciju intervjua kao komunikativnog događaja uvodi obaveze učesnika u konverzaciji koje su nametnute samim tipom konverzacije. Po njenoj definiciji jedan učesnik ima unilateralno pravo da postavlja pitanja, a drugi obavezu da na njih odgovara (1976: 190).

Još su preciznije status učesnika u intervjuu odredili Kress i Fowler. Po njima je taj status neravnopravan - asimetričan. Učesnici se prvenstveno razlikuju prema svojim individualnim ciljevima, statusu i ulogama. Ta se asimetrija ogleda i u samom jeziku. Na osnovu njihovih argumenata vidimo da moć u razgovoru uglavnom ima intervjuer jer ga on kontroliše, dok je intervjuisana osoba u podređenom položaju. (1979: 63-64). IR ${ }^{4}$ započinje razgovor, ima prava da postavlja pitanja i privilegiju da ga završi. On bira temu i određuje koja će pitanja postaviti, kontroliše dužinu trajanja intervjua, kao i koliko će se razgovarati o nekoj određenoj temi ili podtemi. Međutim, i IE može povremeno imati ulogu moćnog sagovornika, bilo da na momenat preuzme dominantnu ulogu, bilo da odbije da odgovori na neko pitanje ili uzvrati pitanjem. Kress i Fowler smatraju da IE može da postavlja pitanja samo u retkim prilikama i samo kada dobije dozvolu za to.

$4 \quad$ U daljem tekstu ćemo koristiti skraćenice: intervjuer - IR, a intervjuisani - IE (ove skraćenice su preuzete iz prakse analize konverzacije). 
Tek se sa pojavom kritičke analize diskursa položaj i uloga učesnika u intervjuu preciznije određuje. Fairclough se nadovezuje na rad kritičkih lingvista i moć u diskursu prvenstveno dovodi u vezu sa učesnicima u diskursu koji kontrolišu i ograničavaju doprinos drugih učesnika koji nemaju moć (2001: 38-39). Ta se ograničenja mogu podeliti na tri tipa: ograničenja po pitanju sadržaja - šta se kaže ili radi, odnosa - društveni odnosi u koje učesnici u diskursu ulaze, i subjekata - uloge koje učesnici mogu da zauzmu u diskursu. Odnosi i subjekti su u tesnoj vezi, a sva tri tipa se u praksi javljaju istovremeno i preklapaju. U intervjuu ti se odnosi ogledaju na sledeći način:

1. Po pitanju sadržaja, IE mora da odgovara na pitanja koja postavlja IR u skladu sa praksom intervjua, a na temu koju je odabrao IR.

2. Po pitanju odnosa, IE mora da se odnosi profesionalno (u odnosu na svoju oblast stručnosti/znanja) i prema slušaocima i prema IR-u prema kojem je u podređenom položaju, i

3. Po pitanju subjekata, dok IR ima ulogu ispitivača, IE preuzima ulogu ispitivanog u intervjuu, kao i ulogu stručnjaka u svojoj oblasti zbog čega je i pozvan na intervju.

Ograničenja i kontrola o kojima Fairclough govori mogu poticati iz dva izvora. To mogu biti, s jedne strane, moćni učesnici u diskursu, a s druge, konvencije samog žanra diskursa, u ovom slučaju intervjua. Međutim, u oba slučaja, bilo direktno ili indirektno, IR ima kontrolu u diskursu jer je u njegovoj moći da odredi tip razgovora koji se vodi, kao i da kroz samo vođenje razgovora kontroliše i ograničava sagovornika, tj. IE. U ovom slučaju govorimo o moći u diskursu.

U knjizi Media discourse Fairclough daje definiciju novinara i iz njegovih reči možemo zaključiti da je uloga novinara/izveštača/intervjuera uloga moćnog učesnika u bilo kom medijskom komunikativnom događaju. Sam žanr mu daje autoritet i pravo da govori. ,The reporter is projected as a figure of authority, someone who knows (has 'the facts'), and someone who has the right to tell." (1995a: 4)

Međutim, i novinari se moraju povinovati nekim pravilima institucionalnog govora. Ovim pitanjem kao i određivanjem strukture intervjua kao konverzacijske forme bavili su se i predstavnici analize konverzacije. Hutchby i Wooffitt porede ulogu ispitivača u sudnici i medijskom intervjuu. Po njima, u oba slučaja ispitivači se moraju uzdržati od iznošenja sopstvenog mišljenja. Oni moraju od onih koje ispituju dobiti njihova mišljenja, stavove ili saopštenja. Glavni razlog je publika, tačnije porota u sudnici, 
odnosno gledaoci/slušaoci intervjua. „For different reasons, the audience in each case is supposed to draw inferences and make judgements about the one being questioned without undue influence from the questioner." (1998: 151) Ovo ograničenje sa kojim se suočavaju ispitivači detaljnije su opisali Clayman i Heritage (2002) i Heritage i Clayman (2010). Naime, svi novinari treba da o novostima izveštavaju objektivno. Tako i intervju kao medijski žanr mora da bude objektivan, a intervjuer kao profesionalni novinar mora da ostane neutralan $u$ interakciji sa ličnostima iz javnog života. Ova neutralnost podrazumeva dva ograničenja. Prvo, intervjuer se ograničava na „traženje informacija“ što dalje podrazumeva da ne sme da izražava svoje mišljenje. I drugo, intervjuer mora da izbegava da iznosi tvrdnje osim ako mu one služe kao put do konačnog pitanja. Takođe se mora uzdržavati od upotrebe tokena za potvrđivanje (uh huh, yeah, oh, okay, right, itd.) dok intervjuisana osoba odgovara na pitanje, jer bi se to moglo protumačiti kao odobravanje onoga što ona govori. Clayman i Heritage primećuju još jednu bitnu odliku intervjua, a to je da se intervjuer mora distancirati u interakciji i da se prilikom razgovora mora uzdržati od ponašanja kao da je on pravi sagovornik svom gostu. Ovo znači da se on služi pitanjima da bi održavao razgovor, ali se ne ponaša kao da je odgovor upućen njemu, već publici koja ga sluša. Ovo je bitna razlika u odnosu na svakodnevnu komunikaciju, gde se, ako potvrdimo da smo nešto čuli ili shvatili, ponašamo kao da je ta replika upućena nama.

Iz svega dosad rečenog može se zaključiti da je osnovni cilj medijskog intervjua proizvodnja komunikativnog čina namenjenog publici, koji se zasniva na sistemu govorne razmene po principu smenjivanja redova govorenja pitanje - odgovor, a u kojem učestvuju IR - profesionalni novinar, koji mora tokom intervjua zardžati strogo formalno neutralnu poziciju kroz postavljanje pitanja, i IE - gost, ličnost iz javnog života, stručnjak ili učesnik u tekućim događajima, koji svoj status održava kroz odgovore na IR pitanja. Odnosi moći se ogledaju u neravnopravnom (asimetričnom) statusu sagovornika, jer intervjuer ima potpunu kontrolu u diskursu.

\section{Konfrontacija}

O pojmu konfrontacije malo je pisano. Čak ni u delima iz oblasti psihologije i sociologije, konfrontacija se ne definiše samostalno već se 
pominje samo u svetlu definisanja konflikta, i to samo sporadično. Potražili smo stoga definicije u enciklopedijama i rečnicima.

Vujaklija daje sledeću definiciju: „Konfrontacija (nl. confrontatio) prav. suočavanje, suočenje, naročito svedoka (nl. confrontatio testium), ili okrivljenih čiji su iskazi protivrečni; poređenje, sravnjivanje, sravnjenje, upoređivanje, upoređenje“" (1966: 479).

U Longman Dictionary of English Language and Culture konfrontacija se definiše kao the act of confronting, especially a situation or manner marked by open opposition (na osnovu definicije glagola confront - to be faced with and have to deal with; confront somebody with something - to force to deal with or accept the truth of; bring face to face with); $i$ confrontational - intentionally causing or likely to cause confrontation; provocative; (2005: 288).

Oxford English Dictionary: Confrontation - the action of confronting, the bringing of persons face to face; esp. for examination and eliciting of the truth (na osnovu definicije glagola confront - to bring together face to face; to bring (a person) face to face with (a person or thing); esp. an accused and his accusers, or the different witnesses in a trial, for examination); i confrontational - characterized by or likely to cause confrontation; aggressive, marked by an adversarial approach (2009).

Konfrontacija predstavlja uvod u konflikt. Konflikt ne može postojati bez konfrontacije, ali sama konfrontacija jos uvek nije ,čist“" konflikt, jer konflikt izrasta iz konfrontacije. Putnam i Poole definišu konflikt kao, the interaction of interdependent people who perceive opposition of goals, aims and values, and who see the other party as potentially interfering with the realization of these goals“ (1987: 552). Oni smatraju da se konflikt sastoji od tri glavne komponente: međusobne zavisnosti, interakcije i nekompatibilnih ciljeva, a one se formiraju i održavaju u društvenoj interakciji. (1987: 552).

U svom delu Psihologija međuljudskih odnosa Bojanović objašnjava kako nastaje konflikt: „Rivalitet dve strane i nesaglasnost osnovnih ciljeva, želja ili vrednosti dovodi do osujećivanja nekih od osnovnih potreba učesnika u konfliktu. Osujećenje potreba je psihičko jezgro i energetska snaga konflikta“" (1998: 224)

Eldridge konflikt opisuje kao situaciju u kojoj je jedan učesnik angažovan (u odnosu na drugoga) u težnji ostvarenja onoga što su, ili što bi trebalo da budu, nekompatibilni ciljevi (u Dittloff i Harris, 1996: 59). 
Van Dijk konflikt u komunikaciji objašnjava kao različito poimanje komunikativne situacije: ,the participants of an interaction, as well as writers and readers in written communication, may not have the same definition of the communicative situation in the first place, as is typically the case, and actually shown in communicative conflicts." (2008: 240)

Konfrontacija, dakle, kao uvod u konflikt, podrazumeva suočavanje, suprotstavljanje, razmimoilaženje u nečemu, ali ne nužno i nastanak konflikta. Ako to značenje primenimo na intervju kao institucionalizovani tip diskursa, zaključujemo da se konfrontacija odnosi na učesnike u komunikaciji i njihove vrednosti, stavove, verovanja, mišljenja. Konfrontacija u ovom slučaju proizilazi iz činjenice da se učesnici konfrontiraju po pitanju ciljeva koje žele da postignu u dijalogu, a sve to u okviru institucionalnog žanra. IR ima samo jedan cilj, a to je da informiše javnost o problemu ili temi o kojoj razgovara sa IE. S druge strane, IE takođe želi (ili mora) da informiše javnost o problemu o kojem je reč, ali njemu je cilj da kaže onoliko koliko on, ili institucija čiji je predstavnik (politička partija, preduzeće, sportska organizacja/klub, neka agencija, i slično), želi. Dakle, ciljevi intervjua su da se javnost informiše o nekom problemu i da se taj problem razjasni, ali individualni ciljevi po pitanju dubine ili detalja problema koji treba da se iznesu nisu kod oba učesnika u komunikaciji isti. Zato dolazi do konfrontacije, i kad, na primer, IR primeti da IE ne želi da odgovori na neko pitanje, primenjuje provokativna pitanja putem kojih se nada da će dobiti odgovor.

To suočavanje, suprotstavljanje, razmimoilaženje, kako smo definisali konfrontaciju podrazumeva, dakle, neslaganje učesnika u interakciji po nekom pitanju. Bitno je ovde napomenuti da se to neslaganje ne ogleda u očiglednom konfliktu, raspravi, čak i svađi, već prvenstveno u elementima koje je na prvi pogled ponekad teško uočiti, a koji pritom uvek predstavljaju kršenje normi koje čine ovaj tip diskursa samosvojnim žanrom.

\section{Diskurs konfrontacionog intervjua}

Videli smo da su IR u početku imali drugačiji status i ulogu u intervjuu nego što je to slučaj danas. Pitanja koja su postavljali bila su prvenst-

veno namenjena za dobijanje činjenica $\mathrm{i}$ informacija, a odgovori inter- 
vjuisanih osoba nisu se dovodili u pitanje. Ličnost IR nije smela doći do izražaja, a naglasak je bio na IE čiji je doprinos bio u središtu interesovanja i nije se dovodio u pitanje.

Neda Todorović kaže da su danas novinari hrabriji nego ranije, i da se ta njihova hrabrost ne ogleda u objavljivanju podataka javnosti, već da „njena suština leži u postavljanju smelih, kvalifikovanih pitanja koja insistiraju na iskrenim odgovorima." (2002: 84) Neda Todorović medijski intervju naziva „novim intervjuom“ iz perspektive njegovog istorijskog razvoja.

Tzv. novi intervju, forma koja dominira modernim medijima, posledica je drugačijih gledanja novinara mlađe generacije na ovu popularnu formu izražavanja. Intervjuer je u pristupu sagovorniku agresivniji, smeliji, manje konvencionalan. Ne drži se pravila strogog protokola koji je ranije vladao između političara (nedodirljivih) i novinara klimoglava. Izuzetno dobro informisan, pošto je u procesu pripreme za intervju iščeprkao i najsitnije detalje iz sagovornikovog života ili pronašao njegove ranije izjave u kojima se kriju nedoslednosti, današnji novinar postavlja direktna pitanja koja podrazumevaju iskrene odgovore. On ne nipodaštava sagovornika ni kada se s njim ne slaže. Njihov razgovor je dijalog jednakih u kome sagovornik ima poslednju reč. (2002: 84-85).

U ovoj definiciji možemo uočiti nekoliko važnih karakteristika konfrontacionog diskursa. Prvo, novinari su agresivniji, smeliji; dobro su informisani i pripremljeni; pitanja su direktna, a poštovanje sagovornika primerno. Jedino u čemu se ova definicija ne slaže sa kritičkom analizom diskursa i sa određenjem konfrontacionog diskursa je da je ovakav intervju razgovor jednakih i da IE ima poslednju reč. Iz naše perspektive, što smo već pokazali, medijski intervjui, pa ni konfrontacioni intervju, nisu razgovori jednakih, već je to asimetričan diskurs u kojem IR ima i prvu i poslednju reč.

Dakle, IR u tom asimetričnom odnosu uloga ima dominantnu ulogu samim tim što ima neprikosnoveno pravo da bira temu razgovora, postavlja pitanja, određuje dužinu trajanja razgovora, ali i svake teme, ako ih ima više. Može da prekine IE ako smatra da ovaj nije odgovorio na pitanje, ili da taj odgovor nije u skladu sa činjenicama, ili nije dovoljno precizan. On takođe može da prekine razgovor o nekoj temi kada smatra da je ona iscrpljena, da vrati razgovor na neku prethodnu temu, ili da spreči IE da temu promeni ili da napravi digresiju, i slično. 
S druge strane, ni IE nije uvek u podređenom položaju. On može da odgovori na pitanje, ali i ne mora, bar ne u potpunosti. Može da izbegne da odgovori na pitanje, ili može da da nepotpun odgovor. Ponekad se dešava da preuzme kontrolu nad diskursom, mada to obično ne traje dugo. ${ }^{5}$

Iz ovoga vidimo kako nastaje konfrontacija u dijalogu, i koji su razlozi njenog nastanka. U istraživanju načina na koji televizijski IR izražavaju moć u konverzaciji, Owsley i Scotton su došle do sledećeg zaključka:

Powerful language is characterized as an aggregate of linguistic features which negotiate a position of ,taking charge“ in a talk exchange: features used in an attempt by one speaker, relative to other participants, to control conversational content, evaluation of that content, and organization of the exchange (who speaks, when, and how long). (1984: 262)

One takođe smatraju da se jezik moći može naći u bilo kom tipu konverzacije, ali da je najčešći u situacijama gde je moć asimetrična, dakle, u institucionalnim okvirima. Svoj izbor televizjskih IR za istraživanje govora moći, obrazlažu činjenicom da oni moć izvode iz same uloge IR, što je institucionalna pozicija, a koja pretpostavlja postavljanje pitanja čin kontrole.

$5 \quad$ Za društvene implikacije koje mogu proizaći iz konfrontacionog intervjua videti Clayman i Heritage 2002. Oni daju za primer dva slučaja u kojima su bilo IR bilo IE imali negativne posledice zbog intervjua u kojima su učestvovali. Prvi je slučaj političara Michael-a Howard-a, u to vreme (1997) glavnog kanditdata za prvog čoveka Konzervativne stranke koga je intervjuisao Jeremy Paxman, britanski novinar. Izbegavši da da odgovore na pitanja o nekim odlukama koje je doneo dok je bio ministar unutrašnjih poslova u vremem premijera John-a Major-a, Howard je izazvao veliko interesovanje i preispitivanje u javnosti, izgubio je vodeće mesto u svojoj stranci, a konkurentska, Laburistička stranka, to je iskoristila za pobedu na izborima. S druge strane, Paxman je imenovan za intervjuera godine. Drugi slučaj je uzdigao političara, a stavio tačku na karijeru novinara. Reč je o devetominutnom intervjuu koji je 1988. vodio američki novinar Dan Rather, a gost mu je bio tadašnji predsednički kandidat George Bush. Intervju se razvio u neprijateljsku konfrontaciju oko Bush-ove umešanosti u Iransku kontra aferu 1985-87. Rather je, zbog agresivnog načina na koji je vodio intervju, u javnosti ocenjen kao „neuljudan" i njegova karijera je bila gotova, a CBS stanica za koju je radio, počela je da gubi na gledanosti. Uzroci za to su sigurno bili dublji, ali je ovaj intervju očigledno bio povod za takav razvoj događaja. S druge strane, Bush je, iako nije na zadovoljavajući način odgovorio na sva delikatna pitanja, pokazao da nije samo poslušnik i senka tadašnjeg predsednika Ronald-a Reagan-a, i tada je prvi put viđen kao neko ko je „pobedio“ Rather-a, ko ima svoj stav i njegova karijera je krenula uzlaznom linijom. Pobedio je na predsedničkim izborima naredne godine. 
Primeri za news intervju koje daju Heritage i Clayman (2010) su Newsnight (UK), Meet the Press (SAD), Nightline (SAD). Newsnight je, na primer, intervju koji se emituje na kanalu BBC kao i Hardtalk i koji se po temama i formi ne razlikuje mnogo od Hardtalk-a. Dužina trajanja varira od samo nekoliko minuta do pola sata, dok je u Hadrtalk intervjuima dužina od 25 minuta fiksna. Razgovor se u oba intervjua bazira na shemi pitanje-odgovor, osim što je element konfrontacije mnogo prisutniji i uočljiviji u Hardtalk intervjuima, što se vidi i u samom nazivu (hard na engleskom znači: tvrd, čvrst, težak, mučan). Zbog toga je Hardtalk tipičan primer konfrontacionog intervjua na engleskom jeziku. Sličan primer za konfrontacioni intervju na srpskom jeziku je Poligraf, pošto je to srpska verzija Hardtalk-a.

\section{Hardtalk - klasični istraživački konfrontacioni intervju}

Konfrontacioni ${ }^{6}$ ili konfrontirajući intervju je novi tip intervjua koji se javlja sa nastankom britanske emisije Hardtalk, koja se od 1997. godine prikazuje na BBC-ju. Na internet sajtu BBC-ja, kao glavna karakteristika Hardtalk emisija, stoji da su to: „In-depth interviews with hard-hitting questions and sensitive topics being covered as famous personalities from all walks of life talk about the highs and lows in their lives." (http://www. bbc.co.uk/programmes/b006mg2m) Na stranici posvećenoj Hardtalk-u, dat je detaljniji opis:

HARDtalk is the hard-hitting flagship news programme shown on BBC World News and the BBC News channel. The half hour interview is the result of detailed research and in-depth investigations. HARDtalk asks the difficult questions and gets behind the stories that make the news - from international political leaders to entertainers; from corporate decision-makers to ordinary individuals facing huge challenges.

(http://news.bbc.co.uk/2/hi/programmes/hardtalk/about_hardtalk/ default.stm)

Osim ovih podataka na BBC sajtu možemo pročitati i reči Stephena Sackur-a, trenutno vodećeg intervjuera Hardtalk-a. Na osnovu toga možemo definisati Hardtalk intervjue:

6 Opredellili smo se za termin konfrontacioni, jer se to uobičajeni oblik prideva u srpskom jeziku, mada je Jugoslav Ćosić, tvorac i urednik Poligrafa u određenju emisije upotrebio termin konfrontirajući. 
1. Učesnici su aktuelni gosti iz raličitih oblasti javnog života:,,Where else do you get half an hour, one-on-one to quiz the men and women who shape our world?"“

2. Tip diskursa je konfrontirajući, pitanja su provokativna:,,It's not about soundbites or political posturing, nor is it a platform for celebs to plug their latest book. It's intelligent talk based on challenging questions. We have the time to dig deeper with our guests. To take them to the territory where the tough questions lie. But it only works if we have done our homework."

Teme su interesantne za gledaoce, dakle javnost je uključena: „HARDtalk isn't about shouting, or point-scoring. It's about asking the intelligent questions our audience would be asking if they had the chance to sit in the HARDtalk chair." (sva tri citata su preuzeta sa web stranice: http://www.bbc.co.uk/programmes/n13xtmdc/profiles/stephen-sackur)

U okviru analize konverzacije rađena su istraživanja o takozvanim neprijateljskim pitanjima (hostile questions). Čini se da naziv nije sasvim odgovarajući. Medijski intervju postoji da bi se publici predočila neka informacija od opšteg interesa. Ako i postoji teškoća u dolaženju do informacije direktno od relevantne ličnosti, novinari ne pribegavaju neprijateljstvu već provokaciji, ili čak agresivnom nastupu u toku ispitivanja, ali se provokacija i agresivnost ipak ne mogu nazvati neprijateljskim ponašanjem. To misli i Stephen-a Sackur i izjavljuje u toku intervjua sa rediteljem Oliver-om Stone-om:

SS:I mean, it's not a question of being hostile and, you know, I interview the people all the time and and hostility isn't the thing, but being rigorous and challenging.

(E19: 15:04)

Možemo zaključiti da je Hardtalk konfrontacioni intervju, u kojem učestvuju novinar istraživač koji je dobro upoznat sa temom i učesnicima i učesnici koji su autoriteti u svojim profesionalnim oblastima. Pritom moramo imati u vidu publiku zbog koje se intervjui i organizuju, a koja je takođe učesnik u komunikativnom događaju. Iako je pasivni učesnik, i ona ima svoju ulogu u diskursu intervjua. 


\section{Poligraf - srpska verzija Hardtalk-a}

Poligraf je klasični istraživački konfrontacioni televizijski intervju nastao po uzoru na BBC-jev Hardtalk i prva je emisija tog tipa koja je svakodnevno emitovana na nekoj od domaćih televizija. Odabir tema, gostiju, kao i način vođenja konverzacije i tip diskursa su isti. Tip diskursa eksplicitno je naveo urednik i voditelj Jugoslav Ćosić na internet stranici televizijskog kanala B92:

Po medijskoj formi POLIGRAF je konfrontirajući intervju. U hardtok tradiciji i sa istraživačkim pristupom, POLIGRAF u fokus stavlja najvažnije političke, društvene, kulturne i socijalne događaje. Kroz atraktivan dijalog, uvek sa jednim gostom, nudi vrhunske analize najvažnijih događaja i fenomena, značajnih za život građana. (http://www.b92.net/lica/ bio.php?nav_id=211661)

U pitanju je dakle konfrontacioni tip diskursa, a navode se i oblasti iz kojih se vrši odabir tema. Isto određenje javlja se i četiri godine kasnije: „Već četiri godine Antonela Riha i Jugoslav Ćosić svakog radnog dana u sedam, u konfrontirajućim intervjuima sa aktuelnim gostima - analiziraju priče koje stoje iza vesti.“ (http://www.b92.net/info/vesti/index. php?yyyy=2009\&mm=06\&dd=19\&nav_category=15\&nav_id=366907), s tim što je ovde naglasak stavljen na aktuelnost tema i gostiju, kao i na činjenicu da se u intervjuima može saznati više nego u redovnim vestima, što se podudara sa informacijom koju možemo naći na stranici Hardtalk-a. Već sam taj podatak nam govori da način za dobavljanje takvih informacija nije konvencionalan, i ovde možemo da se pozovemo na opis Hardtalk pitanja kao „challenging“, u prevodu ,provokativan“.

Kao što možemo da iz gorenavedenog zaključimo radi se o istom tipu intervjua, aktuelnom, konfrontirajućem, istraživačkom.

\section{Intervju kao institucionalni diskurs}

Bitna odlika svakog medijskog intervjua je institucionalnost. Institucionalni govor u većem obimu proučavan je u okviru analize konverzacije.

$7 \quad$ Poligraf se emitovao od septembra 2005. do juna 2009. godine. Jugoslav Ćosić je nakon što je Poligraf prestao da se emituje nastavio sa istim stilom intervjuisanja u emisiji Između dve vatre. 
Drew i Heritage smatraju da je termin 'institutional interaction' bolji od 'institutional talk' i definišu ga: ,the institutionality of an interaction is not determined by its setting. Rather, interaction is institutional insofar as participants' institutional or professional identities are somehow made relevant to the work activities in which they are engaged." (1992: 3-4) Međutim, institucionalni govor se ne može izdvojiti iz njegovog institucionalnog okruženja, odnosno konteksta. Gumperz smatra da je institucionalni govor 'situated' (1982) i kao takav se samo i može proučavati.

U svoju definiciju intervjua Herritage uključuje njegov institucionalni karakter. Intervju je po njemu ,functionally specialized form of social interaction produced for an overhearing audience and restricted by institutionalized conventions“" (1985: 112).

Mada se institucionalni govor razlikuje od svakodnevnog razgovornog jezika, Fairclough primećuje da je u poslednje vreme došlo do „konverzacionalizacije" institucinalnog govora (Fairclough, 1992: 205, 1994). Formalni stil sve više ustupa mesto razgovornom, manje formalnom stilu, koji je bliži širokim narodnim masama, na primer, gledaocima i slušaocima različitih medija. Prema Fairclough i Wodak (1997) i Fairclough (2001: 180-184) društveno-kulturne i jezičke promene teku naporedo.

Discursive change is analysed in terms of creative mixing of discourses and genres in texts, which leads over time to the restructuring of relationships between different discursive practices within and across institutions, and the shifting of boundaries within and between 'orders of discourse'. (Fairclough i Wodak, 1997: 265)

Kao primer za veliku promenu koja pogađa javne institucije u savremenom društvu, oni navode: ,the ‘conversationalization' of public discourse, the simulation of conversational practices in public domains, shifting the boundary between the orders of discourse of public life and ordinary life.“ (1997: 265) Ovo je veoma jasno vidljivo i u medijskom intervjuu koji je pretrpeo znatne promene od početaka do danas.

Institucionalni govor su proučavali mnogi autori, mahom predstavnici kritičke analize diskursa i analize konverzacije. Proučavana je struktura interakcije u, da pomenemo samo neke, sudnicama (Atkinson i Drew, 1979), učionicama (McHoul, 1978) i intervjuima (Greatbatch, 1988). Došlo se do zaključka da je za određivanje strukture interakcije od značaja proučavanje preuzimanja redova govorenja. Heritage i Greatbatch ukazuju na razliku između svakodnevne konverzacije i institucionalnog 
govora: ,the institutional character of the interaction is embodied first and foremost in its form - most notably in turn-taking systems which depart substantially from the way in which turn-taking is managed in conversation" (1991: 95). Mada su redovi govorenja bitni i u svakodnevnoj interakciji, za određivanje strukture pojedinih žanrova oni su od ključnog značaja. Organizacija redova govorenja je ovde od metodološkog značaja, jer se po njima instuticionalna interakcija razlikuje od svakodnevne. U sudnici, učionici ili bilo kom tipu intervjua preuzimanje redova govorenja se vrši po normama, i ako se od njih odstupi, narušava se i struktura žanra, pa u pojedinim slučajevima više ne možemo ni govoriti o žanru.

Pored redova govorenja, postoje i druge razlike između institucionalne i svakodnevne interakcije. One podrazumevaju ograničavanje mogućnosti i opcija karakterističnih za razgovorni jezik, a sastoje se od „specializations and respecifications of the interactional functions of the activities that remain. The ensemble of these variations from conversational practice may contribute to a unique 'fingerprint' for each institutional form of interaction" (Drew i Heritage, 1992: 26). Taj 'otisak prsta' predstavlja skup praksi u interakciji koji razlikuje jedan institucionalni žanr od ostalih, s jedne, i od svakodnevne konverzacije, s druge strane. U diskursu koji ovde proučavamo to je pre svega kontinuirano ponavljanje blizanačkih parova pitanje - odgovor.

Kada govorimo o medijskom intervjuu osnovna struktura preuzimanja redova govorenja je jednostavna: IR: pitanje; IE: odgovor; IR: sledeće pitanje; IE: odgovor itd. Međutim, ovo nije samo po sebi dovoljno da se ovaj tip intervjua odredi i prepozna, tj. razlikuje od drugih oblika institucionalnog diskursa čija se osnovna struktura takođe zasniva na shemi pitanje - odgovor (na primer interakcija u sudnici). Da bi se to postiglo, mora se odrediti i sveukupna strukturna organizacija interakcije. Gotovo svi oblici institucionalnog govora, za razliku od svakodnevne konverzacije, imaju specifičnu organizaciju, ili redosled određenih faza u interakciji. U svakodnevnoj konverzaciji ne postoji unapred utvrđeni redosled faza po kojima se ona odvija. Nasuprot tome: ,[t] $[$ he activities conducted in many kinds of institutional interactions [...] are often implemented through a task-related standard shape.“ (Drew i Heritage, 1992: 43). 


$$
\begin{aligned}
& \text { IR - Uvod } \\
& \text { IR - Pozdrav } \\
& \text { IE - Pozdrav } \\
& \text { IR - Prvo pitanje } \\
& \text { IE - Odgovor } \\
& \text { IR - Drugo pitanje } \\
& \text { IE - Odgovor } \\
& \text { I. } \\
& \text { I tako dalje nepromenjenim redosledom do kraja intervjua. } \\
& \text { IR - Pozdrav } \\
& \text { IE - Pozdrav }
\end{aligned}
$$

Slika 1. Struktura žanra klasičnog intervjua.

Heritage i Clayman smatraju da su redovi govorenja u samom središtu intervjua kao žanra. Kao i svaka druga vrsta institucionalnog govora koja ima specijalizovan sistem govorne razmene (kao što su govor $\mathrm{u}$ sudnici, u lekarskoj ordinaciji, ili u školi, itd.), tako i news inteview ima strukturu po kojoj je prepoznatljiv kao poseban žanr, po kojoj se razlikuje od drugih žanrova, ali i od svakodnevne interakcije (2010: 215-226). Ovo smo prikazali na slici 1 .

Ovde se moramo osvrnuti i na osnovne norme klasičnog intervjua, a koje su detaljno odredili Heritage i Clayman (2010). Osnovne norme kojih se učesnici u intervjuu moraju pridržavati odnose se (I) na opštu strukturu interakcije, i na (II) strukturu preuzimanja redova govorenja, odnosno uzimanja reči.

(I) Kada govorimo o opštoj strukturi interakcije, norme su sledeće:

1) Interakcija se odvija po shemi pitanje - odgovor, pri čemu IR postavlja pitanja, a IE na njih odgovara;

2) Ta shema određuje i ograničava ponašanje učesnika u interakciji: kad mogu da preuzmu reč, koliko dugo mogu da govore, i slično;

3) Ovaj žanr, kao institucionalna interakcija, postavlja dva specifična zahteva, a to su:

a. postojanje publike - što povlači za sobom zahtev da se interakcija organizuje kao „razgovor za slušaoce“, tako da publika nema osećaj da prisustvuje privatnom razgovoru, već da se taj razgovor vodi baš zbog nje; i 
b. održavanje formalne neutralnosti IR - što znači da IR, kao profesionalni novinar, ne sme ni na koji način da izražava svoje mišljenje, ili mišljenje organizacije u kojoj je zaposlen. (2010: 215-216)

(II) Kada govorimo o strukturi preuzimanja redova govorenja, norme su sledeće:

1) interakcija se mora ograničiti na pitanja i odgovore, $i$ to

a. IR se mora ograničiti na postavljanje pitanja,

b. IE se mora ograničiti na davanje odgovora na postavljena pitanja;

2) IR postavlja pitanje, koliko god to vremena zahtevalo (sam pojam pitanja je veoma širok i obuhva čitav niz mogućnosti, o čemu će biti reči kasnije);

3) IE čeka da IR završi, odnosno da čuje celo pitanje na koje treba da odgovori;

4) IE odgovara na pitanje, i taj odgovor je po pravilu elaboriran;

5) IR čeka da IE završi svoj odgovor, pa zatim postavlja sledeće pitanje.

Ovako postavljene norme i pridržavnje normi od strane učesnika u interakciji podrazumevanju dominantnu ulogu IR. Do promena odnosa moći i preuzimanja dominacije, bar na mahove, dolazi tek kad se od normi odstupi. Svako odstupanje od ovih normi podrazumeva neku vrstu konfrontacije.

Institucionalni govor se nalazi u osnovi odnosa moći, $\mathrm{i}$ da bi se u potpunosti mogao razumeti, ti odnosi se moraju eksplicitno izraziti. Fairclough upućuje na različita značenja termina „moć“. Ograđujući se od moguće interpretacije njegovih shvatanja moći kao isključive moći jezika, on ukazuje na razliku između fizičke i institucionalne moći. Za razliku od fizičke moći koja se ispoljava kroz prinudu na različite načine, uključujući i fizičko nasilje, institucionalna moć se sprovodi kroz ideologiju tako što se prethodno obezbedi pristanak učesnika u određenom institucionalnom okruženju (2001: 3).

Fairclough ukazuje na takozvanu 'tehnologizaciju diskursa' ili 'diskursne tehnologije', koje preuzima od Foucault-a. On smatra da se Foucault-ova analiza tehnologija ${ }^{8}$ moći može proširiti na diskurs. Kao primere

8 U nedostatku boljeg termina zadržaćemo termine tehnologija, tehnološki kao prevod engleskih termina technology i technological, kao i tehnologizacija za termin technologization. 
za diskursne tehnologije on navodi intervju, podučavanje, savetovanje i reklamiranje, koje prvenstveno nalazimo u institucionalnim okvirima, i koji imaju svoje 'tehnologe': istraživače koji se bave njihovom efikasnošću, poboljšanjem i konačno, promenama u institucionalnom okruženju. Ove tehnologije dovode u blisku vezu znanje o jeziku i diskursu sa moći. Fairclough kaže:

They are designed and refined on the basis of the anticipated effects of even the finest details of linguistic choices in vocabulary, grammar, intonation, organization of dialogue, and so forth, as well as facial expression, gesture, bodily stance, and movements. They bring about discursive change through conscious design. (1992: 216)

\section{Zaključak}

Iz svega dosad navedenog možemo zaključiti da je konfrontacioni intervju komunikativni događaj koji se odvija u formi dijaloga kroz pitanja i odgovore, između predstavnika medija, tj. profesionalnog novinara i osobe relevantne za aktuelne događaje, čija je svrha informisanje javnosti. Odnosi moći se ogledaju u neravnopravnom (asimetričnom) statusu sagovornika, jer intervjuer ima potpunu kontrolu u diskursu. Teme o kojima se razgovara su aktuelne i interesantne za javnost. Sve do ove tačke definicija konfrontacionog intervjua podudara se sa definicijom klasičnog intervjua. Međutim, oni se razlikuju u nekoliko bitnih tačaka. Prvo, u konfrontacionom intervjuu dolazi do odstupanja od strukture klasičnog intervjua. U konfrontacionom diskursu sagovornici se ne pridržavaju uvek normi klasičnog intervjua. Oni narušavaju strukturu interakcije iz klasičnog intervjua time što u momentima konfrontacije odstupaju od sheme pitanje -odgovor. Nije retko da IE na pitanje odgovori pitanjem, pa se IR nađe u situaciji da odgovara na pitanje. U tim momentima se narušavaju i odnosi moći, tj. IR više ne kontroliše tok diskursa, već IE preuzima kontrolu, makar na kratko. Što se tiče održavanja neutralnosti IR, u trenucima konfrontacije IR može da izgubi neutralnost i da iznese svoje mišljenje. Zatim, kada govorimo o strukturi preuzimanja redova govorenja u konfrontacionom intevjuu sagovornici se retko striktno pridržavaju nesmetanog preuzimanja, pa tako često niti IR postavi pitanje do kraja, a IE ga prekida jer 
želi da pitanje prekine ili ga preinači, niti IE može da dovrši svoj odgovor jer ga IR prekida jer smatra da IE pokušava da izbegne da odgovori na postavljeno pitanje. Stoga sagovornici jedan drugome upadaju u reč, tj. prekidaju sagovornike i ne dozvoljavaju im da dovrše započeto, često dolazi do preklapanja redova govorenja, tj. oba sagovornika govore u isto vreme, pa je ponekad teško pratiti dijalog, a u ekstremnijim slučajevima jedan od sagovornika, ili oba, mogu podići glas ili stupiti u otvorenu konfrontaciju. Konfrontacija je osnovni element po kojem se ova dva tipa intervjua razlikuju. Ona nastaje usled nepodudarnosti ciljeva učesnika u ovom komunikativnom činu, jer novinar ima za cilj da dođe do što potpunijih i tačnijih informacija o određenoj temi, dok je cilj njegovog sagovornika da pruži samo onoliko informacija koliko on smatra za shodno.

Konfrontacioni intervju predstavlja izuzetno plodno tlo za dalja istraživanja odnosa moći u diskursu, naročito institucionalnom diskursu, za analizu jezičkih sredstava kojima se ti odnosi narušavaju i to u okviru različitih naučnih disciplina. Pored kritičke analize diskursa i analize konverzacije, on može biti predmet interdisciplinarnih istraživanja kako u lingvistici, tako i u drugim naučnim disciplinama kao što su sociologija, psihologija, komunikologija, politikologija, novinarstvo i etnometodologija.

\section{Literatura}

Atkinson, J.M. \& Drew, P. (1979). Order in Court: The Organisation of Verbal Interaction in Judicial Settings. London: Macmillan.

Bojanović, R. (1998). Psihologija međuljudskiho dnosa. Beograd: Centar za primenjenu psihologiju.

Clayman, S. and Heritage, J. (2002). The News Interview.Cambridge: Cambridge University Press.

Day, R. (1961). Television: A personal report. London: Hutchinson.

Dittloff, S. A. \& Harris, K. L. (1996). A contingency approach to understanding negotiator behaviour as a function of world mindedness and expected future interaction. The Journal of Psychology, 130. (pp. 59-70).

Drew, P. \& Heritage, J. (1992). Talk at Work: Interaction in Institutional Settings. Cambridge: Cambridge University Press.

Đurić, D. (1997). Novinarska enciklopedija. Beograd: BMG

Fairclough, N. (1992a). Discourse and Social Change. Cambridge: Polity Press. 
Fairclough, N. (1994). Conversationalization of public discourse and the authority of the consumer. in R. Keat, N. Whitely and N. Abercrombie (Eds.). The authority of the consumer. (pp. 253-268). London: Routledge.

Fairclough, N. (1995a) Media Discourse, London: Edward Arnold.

Fairclough, N. (2001). Language and Power. $2^{\text {nd }}$ edition, London: Pearson Education.

Fairclough, N. \& Wodak, R. (1997). Critical Discourse Analysis. in T. van Dijk (ed.) Discourse as Social Interaction (pp. 258-284). London: SAGE.

Greatbatch, D. (1988). A Turn-Taking System for British News Interviews. Language in Society, 17(3): 401-430.

Gumperz, John J. (1982). Discourse Strategies. Cambridge: Cambridge University Press.

Heritage, J. (1985). Analyzing news interviews: Aspects of the production of talk for an overhearing audience. In Teun A. van Dijk (Ed.), Handbook of discourse analysis, vol. 3 (pp. 95-119). New York: Academic Press.

Heritage, J. \& Clayman, S. (2010). Talk in Action. Interactions, identities, and institutions. Chichester: Wiley-Blackwell.

Heritage, J. \& Greatbatch, D. (1991). On the institutional character of institutional talk: the case of news interviews. In D. Boden and D.H. Zimmerman (eds.). Talk and Social Structure. Berkeley: University of California Press. (pp. 93-117).

Hutchby, I. and Wooffitt, R. (1998) Conversation Analysis. Cambridge: Polity Press.

Kljajić, V. (2009). Intervju: u štampi, u on-line magazinima, na internetu. Beograd: Fakultet političkih nauka, Čigoja štampa.

Kress, G and Fowler, R. (1979). Interviews. In Fowler, R et al. (eds.), Language and control, 63-80. London: Routledge and Kegan.

Leksikon filmskih i televizijskih pojmova (1993). Beograd: Univerzitet umetnosti u Beogradu.

Longman Dictionary of English Language and Culture (2005). Harlow: Pearson Education.

McHoul, A. (1978). The organisation of turns at formal talk in the classroom. Language and Society, 19: 183-213.

Owsley, H.H. \& Scotton, C.M. (1984). The Conversational Expression of Power by Television Interviewers. Journal of Social Psychology, 123. (pp. 261-271).

Oxford English Dictionary Second Edition on CD-ROM (v. 4.0.0.2). (2009). Oxford: Oxford University Press.

Putnam, L. L. \& Poole, M. S. (1987). Conflict and Negotiation. In Jablin, F. M., Roberts, K. H., \& Porter, L. W. (Eds.), Handbook of Organizational Communication, (pp. 549-599). Newbury Park, CA: Sage.

Schegloff, Emanuel A. (1992). On talk in institutional occasions. In P. Drew and J. Heritage (Eds.) Talk at Work. Cambridge: Cambridge University Press, 101-134. 
Todorović, Neda (2002). Interpretativno i istraživačko novinarstvo. Beograd: Fakultet političkih nauka.

van Dijk, T. A. (2008). Discourse and Power. Basingstoke and New York: Palgrave, Macmillan.

Vujaklija, M. (1966). Leksikon stranih reči i izraza. Beograd: Prosveta.

Wedell, E. G. (1968). Broadcasting and public policy. London: Michael Joseph.

Wolfson, N. (1976). Speech events and natural speech: some implications for sociolinguistic methodology. Language in Society, 5. (pp 189-209).

\section{Internet strane}

BBC, Hardtalk, zvanična internet strana. Dostupno preko:

http://www.bbc.co.uk/programmes/b006mg2m

http://news.bbc.co.uk/2/hi/programmes/hardtalk/about_hardtalk/default.stm

http://www.bbc.co.uk/programmes/n $13 \times$ tm dc/profiles/stephensackur[20.12.2017]

B92, Poligraf, zvanična internet strana.Dostupno preko:

http://www.b92.net/lica/bio.php?nav_id=211661

http://www.b92.net/info/vesti/index.php?yyyy $=2009 \& \mathrm{~mm}=06 \& d d=19 \&$ nav category $=15 \&$ nav_id $=366907[20.12 .2017]$

Melina Nikolić

\section{Summary}

\section{AN ATTEMPT AT DEFINING THE CONFRONTATIONAL INTERVIEW}

Discourse of power has been a point of interest of a great number of scholars from various disciplines, and particularly Critical Discourse Analysis. Institutional discourse has been regarded as a source of power relations and consequently of the discourse of power. Particular attention has been given to media discourse, notably the news interview. However, this media genre is usually taken for granted, and the researchers have not really attempted to define it. In this paper we have attempted to provide a definition of a specific form of media interview that is becoming increasingly more present on television programmes all over the world. In this type of interview the interviewers, as media representatives, confront the interviewees, who are in the focus of media attention, trying to elicit not only the answers the interviewees are ready to provide, but also those answers they are reluctant or unwilling to disclose. In order to provide a comprehensive definition 
of this type of interview we have analysed the notions of interview, institutional discourse, confrontation and positioning in discourse, and made a comparison between the 'regular' news interview and the confrontational interview from the perspective of Critical Discourse Analysis and Conversation Analysis.

Key words: interview, institutional discourse, confrontation, critical discourse analysis, conversationa analysis 